IRA-International Journal of Applied Sciences

ISSN 2455-4499; Vol.04, Issue 02 (2016)

Institute of Research Advances

Pg. no. 259-263

http://research-advances.org/index.php/IRAJAS

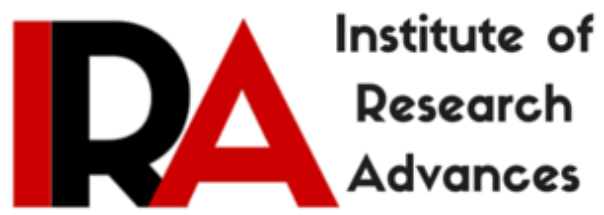

\title{
Generalized Binary Regular Closed Sets
}

\author{
${ }^{1} \mathrm{~S}$. Nithyanantha Jothi \\ Department of Mathematics, Aditanar College, \\ Tiruchendur - 628216, Tamil Nadu, India. \\ ${ }^{2}$ P. Thangavelu \\ Department of Mathematics, Karunya University, \\ Coimbatore - 641 114, India.
}

Type of Review: Peer reviewed.

DOI: http://dx.doi.org/10.21013/jas.v4.n2.p6

\section{How to cite this paper:}

Jothi, S., \& Thangavelu, P. (2016). Generalized Binary Regular Closed Sets. IRAInternational Journal of Applied Sciences (ISSN 2455-4499), 4(2), 259-263. doi:http://dx.doi.org/10.21013/jas.v4.n2.p6

(C) Institute of Research Advances

\section{(cc) BY-NC}

This work is licensed under a Creative Commons Attribution-Non Commercial 4.0 International License subject to proper citation to the publication source of the work.

Disclaimer: The scholarly papers as reviewed and published by the Institute of Research Advances (IRA) are the views and opinions of their respective authors and are not the views or opinions of the IRA. The IRA disclaims of any harm or loss caused due to the published content to any party. 


\section{ABSTRACT}

Recently the authors introduced the concept of binary topology between two sets and investigate its basic properties where a binary topology from $X$ to $Y$ is a binary structure satisfying certain axioms that are analogous to the axioms of topology. In this paper we introduce and study generalized binary regular closed sets.

Keywords: Binary regular open, binary regular closed, generalized binary regular closed and generalized binary regular open.

MSC 2010:54A05, 54A99.

\section{Introduction}

The authors [4] introduced the concept of binary topology and discussed some of its basic properties. Generalized closed sets in topological space are introduced by Norman Levine [7].

Regular generalized closed sets and regular generalized open sets in a topological space are introduced by N.Palaniappan [9]. The authors [8] introduced the concept of generalized binary closed sets in binary topological spaces and study some of its basic properties. In this paper we introduce generalized binary regular closed sets and generalized binary regular open sets in binary topological spaces and their basic properties are studied. Section 2 deals with basic concepts. Binary regular open sets, binary regular closed sets, generalized binary regular closed sets and generalized binary regular open sets in binary topological spaces are discussed in section 3. Throughout the paper, $\wp(\mathrm{X})$ denotes the power set of $\mathrm{X}$.

\section{Preliminaries}

Let $\mathrm{X}$ and $\mathrm{Y}$ be any two nonempty sets. A binary topology [4] from $\mathrm{X}$ to $\mathrm{Y}$ is a binary structure $\mathrm{M} \subseteq \wp(\mathrm{X}) \times \wp(\mathrm{Y})$ that satisfies the axioms namely (i) $(\varnothing, \varnothing)$ and $(\mathrm{X}, \mathrm{Y}) \in \mathrm{M}$, (ii) $\left(\mathrm{A}_{1} \cap \mathrm{A}_{2}, \mathrm{~B}_{1} \cap \mathrm{B}_{2}\right) \in \mathrm{M}$ whenever $\left(A_{1}, B_{1}\right) \in M$ and $\left(A_{2}, B_{2}\right) \in M$, and (iii) If $\left\{\left(A_{\alpha}, B_{\alpha}\right): \alpha \in \Delta\right\}$ is a family of members of $M$, then $\left(\bigcup_{\alpha \in \Delta} \mathrm{A}_{\alpha}, \bigcup_{\alpha \in \Delta} \mathrm{B}_{\alpha}\right) \in \mathrm{M}$. If $\mathrm{M}$ is a binary topology from $\mathrm{X}$ to $\mathrm{Y}$ then the triplet $(\mathrm{X}, \mathrm{Y}, \mathrm{M}$ ) is called a binary topological space and the members of $\mathrm{M}$ are called the binary open subsets of the binary topological space $(\mathrm{X}, \mathrm{Y}, \mathrm{M})$. The elements of $\mathrm{X} \times \mathrm{Y}$ are called the binary points of the binary topological space $(X, Y, M)$. If $Y=X$ then $M$ is called a binary topology on $X$ in which case we write $(X, M)$ as a binary topological space. The examples of binary topological spaces are given in [4].

Definition 2.1.[4]Let $X$ and $Y$ be any two nonempty sets and let $(A, B)$ and $(C, D) \in \wp(X) \times \wp(Y)$. We say that $(\mathrm{A}, \mathrm{B}) \subseteq(\mathrm{C}, \mathrm{D})$ if $\mathrm{A} \subseteq \mathrm{C}$ and $\mathrm{B} \subseteq \mathrm{D}$.

Definition 2.2.[4] Let ( $X, Y, M$ ) be a binary topological space and $A \subseteq X, B \subseteq Y$. Then $(A, B)$ is called binary closed in $(\mathrm{X}, \mathrm{Y}, \mathrm{M})$ if $(\mathrm{X} \backslash \mathrm{A}, \mathrm{Y} \backslash \mathrm{B}) \in \mathrm{M}$.

Proposition 2.3. [4] Let $(\mathrm{X}, \mathrm{Y}, \mathrm{M})$ be a binary topological space and $(\mathrm{A}, \mathrm{B}) \subseteq(\mathrm{X}, \mathrm{Y})$.

Let $(\mathrm{A}, \mathrm{B})^{1 *}=\cap\left\{\mathrm{A}_{\alpha}:\left(\mathrm{A}_{\alpha}, \mathrm{B}_{\alpha}\right)\right.$ is binary closed and $\left.(\mathrm{A}, \mathrm{B}) \subseteq\left(\mathrm{A}_{\alpha}, \mathrm{B}_{\alpha}\right)\right\}$ and

$(\mathrm{A}, \mathrm{B})^{2 *}=\cap\left\{\mathrm{B}_{\alpha}:\left(\mathrm{A}_{\alpha}, \mathrm{B}_{\alpha}\right)\right.$ is binary closed and $\left.(\mathrm{A}, \mathrm{B}) \subseteq\left(\mathrm{A}_{\alpha}, \mathrm{B}_{\alpha}\right)\right\}$. Then $\left((\mathrm{A}, \mathrm{B})^{1 *},(\mathrm{~A}, \mathrm{~B})^{2 *}\right)$ is binary closed and $(\mathrm{A}, \mathrm{B}) \subseteq\left((\mathrm{A}, \mathrm{B})^{1 *},(\mathrm{~A}, \mathrm{~B})^{2 *}\right)$. 
Definition 2.4. [4] The ordered pair $\left((\mathrm{A}, \mathrm{B})^{1 *},(\mathrm{~A}, \mathrm{~B})^{2 *}\right)$ is called the binary closure of $(\mathrm{A}, \mathrm{B})$, denoted by b-cl $(\mathrm{A}, \mathrm{B})$ in the binary space $(\mathrm{X}, \mathrm{Y}, \mathrm{M})$ where $(\mathrm{A}, \mathrm{B}) \subseteq(\mathrm{X}, \mathrm{Y})$.

Definition 2.5. Let $\mathrm{X}$ and $\mathrm{Y}$ be any two nonempty sets and let $(\mathrm{A}, \mathrm{B})$ and $(\mathrm{C}, \mathrm{D}) \in \wp(\mathrm{X}) \times \wp(\mathrm{Y})$. We say that $(\mathrm{A}, \mathrm{B}) \not \subset(\mathrm{C}, \mathrm{D})$ if one of the following holds :

(i) $\mathrm{A} \subseteq \mathrm{C}$ and $\mathrm{B} \not \subset \mathrm{D}$ (ii) $\mathrm{A} \not \subset \mathrm{C}$ and $\mathrm{B} \subseteq \mathrm{D}$ (iii) $\mathrm{A} \not \subset \mathrm{C}$ and $\mathrm{B} \not \subset \mathrm{D}$.

Definition 2.6.[8] Let $(\mathrm{X}, \mathrm{Y}, \mathrm{M})$ be a binary topological space. Let $(\mathrm{A}, \mathrm{B}) \in \wp(\mathrm{X}) \times \wp(\mathrm{Y})$. Then $(\mathrm{A}, \mathrm{B})$ is called generalized binary closed if $\mathrm{b}-\mathrm{cl}(\mathrm{A}, \mathrm{B}) \subseteq(\mathrm{U}, \mathrm{V})$ whenever $(\mathrm{A}, \mathrm{B}) \subseteq(\mathrm{U}, \mathrm{V})$ and $(\mathrm{U}, \mathrm{V})$ is binary open in $(\mathrm{X}, \mathrm{Y}, \mathrm{M})$.

\section{Generalized binary regular closed sets}

We begin this section with the definitions of binary regular open and binary regular closed sets in binary topological spaces.

Definition 3.1. Let ( $X, Y, M$ ) be a binary topological space. Let $(A, B) \subseteq(X, Y)$. Then $(A, B)$ is called binary regular open if $(A, B)=b$-int $(b-c l(A, B))$ and binary regular closed if $(A, B)=b-c l(b-i n t(A, B))$.

Proposition 3. 2. Every binary regular open set is binary open.

Proof. Let $(A, B)$ be binary regular open in a binary topological space ( $\mathrm{X}, \mathrm{Y}, \mathrm{M})$. We shall show that $(A, B)$ is binary open. Since $(A, B)$ is binary regular open, we have $(A, B)=b$-int $(b-c l(A, B))$. Therefore, $(A, B) \subseteq$ b-int $(A, B)$, since $(A, B) \subseteq b-c l(A, B)$. But b-int $(A, B) \subseteq(A, B)$.This implies $(A, B)=b$-int $(A, B)$. Thus, $(\mathrm{A}, \mathrm{B})$ is binary open.

The converse of Proposition 3.2 is not true. This is shown in the following example.

Example 3.3. Let $X=\{0,1\}, Y=\{a, b, c\}$. Clearly $M=\{(\varnothing, \varnothing),(\{0\},\{a\}),(\{1\},\{b\}),(X,\{a, b\}),(X, Y)\}$ is a binary topology from $X$ toY. Also $(\varnothing, \varnothing),(X, Y),(\{1\},\{b, c\}),(\varnothing,\{c\})$ and $(\{0\},\{a, c\})$ are the binary closed sets in $(X, Y, M)$. The binary regular open sets are $(\varnothing, \varnothing),(\{0\},\{a\}),(\{1\},\{b\}),(X, Y)$, since b$\operatorname{int}(\mathrm{b}-\operatorname{cl}(\varnothing, \varnothing))=(\varnothing, \varnothing), \mathrm{b}-\operatorname{int}(\mathrm{b}-\operatorname{cl}(\{0\},\{\mathrm{a}\}))=\mathrm{b}-\operatorname{int}(\{0\},\{\mathrm{a}, \mathrm{c}\})=(\{0\},\{\mathrm{a}\}), \mathrm{b}-\operatorname{int}(\mathrm{b}-\operatorname{cl}(\{1\},\{\mathrm{b}\}))=\mathrm{b}-\operatorname{int}$ $(\{1\},\{b, c\})=(\{1\},\{b\})$ and $b-\operatorname{int}(b-c l(X, Y))=(X, Y)$. Here, $(X,\{a, b\})$ is binary open but not binary regular open .

Definition 3.4. Let $(X, Y, M)$ be a binary topological space. Let $(A, B) \subseteq(X, Y)$. Then $(A, B)$ is called generalized binary regular closed if $\mathrm{b}-\mathrm{cl}(\mathrm{A}, \mathrm{B}) \subseteq(\mathrm{U}, \mathrm{V})$ whenever $(\mathrm{A}, \mathrm{B}) \subseteq(\mathrm{U}, \mathrm{V})$ and $(\mathrm{U}, \mathrm{V})$ is binary regular open.

Proposition 3. 5 If (A, B) is generalized binary closed, then $(A, B)$ is generalized binary regular closed. Proof. Let $(A, B)$ be generalized binary closed in a binary topological space (X,Y,M ). Suppose $(\mathrm{A}, \mathrm{B}) \subseteq(\mathrm{U}, \mathrm{V})$ where $(\mathrm{U}, \mathrm{V})$ is binary regular open. By Proposition3.2, we have $(\mathrm{U}, \mathrm{V})$ is binary open. Since $(A, B)$ is generalized binary closed, we have b-cl $(A, B) \subseteq(U, V)$. Therefore, $(A, B)$ generalized binary regular closed.$\square$

Thus we have the implications

Binary closed $\rightleftarrows$ generalized binary closed $\Longrightarrow$ eneralized binary regular closed

The converse of Proposition 3.5 is not true. This is shown in the following example.

Example 3. 6. If $(A, B)$ generalized binary regular closed, then $(A, B)$ need not be generalized binary closed. For, let $\mathrm{X}=\{0,1\}, \mathrm{Y}=\{\mathrm{a}, \mathrm{b}, \mathrm{c}\}$. Clearly $\mathrm{M}=\{(\varnothing, \varnothing),(\{0\},\{\mathrm{a}\}),(\{1\},\{\mathrm{b}\}),(\mathrm{X},\{\mathrm{a}, \mathrm{b}\}),(\mathrm{X}, \mathrm{Y})\}$ is a 
binary topology from $X$ to $Y$. Also $(\varnothing, \varnothing),(X, Y),(\{1\},\{b, c\}),(\varnothing,\{c\})$ and $(\{0\},\{a, c\})$ are the binary closed sets in $(\mathrm{X}, \mathrm{Y}, \mathrm{M})$.

The binary regular open sets are $(\varnothing, \varnothing),(\{0\},\{a\}),(\{1\},\{b\}),(X, Y)$, since b-int $(b-c l(\varnothing, \varnothing))=(\varnothing, \varnothing)$, $\mathrm{b}-\operatorname{int}(\mathrm{b}-\mathrm{cl}(\{0\},\{\mathrm{a}\}))=\mathrm{b}-\operatorname{int}(\{0\},\{\mathrm{a}, \mathrm{c}\})=(\{0\},\{\mathrm{a}\}), \mathrm{b}-\operatorname{int}(\mathrm{b}-\mathrm{cl}(\{1\},\{\mathrm{b}\}))=\mathrm{b}-\operatorname{int}(\{1\},\{\mathrm{b}, \mathrm{c}\})=(\{1\},\{\mathrm{b}\})$ and b- int $(\mathrm{b}-\mathrm{cl}(\mathrm{X}, \mathrm{Y}))=(\mathrm{X}, \mathrm{Y})$. Now, consider $(\mathrm{X}, \varnothing) \in \wp(\mathrm{X}) \times \wp(\mathrm{Y})$. Clearly, $(\mathrm{X}, \varnothing) \subseteq(\mathrm{X}, \mathrm{Y})$ where $(\mathrm{X}, \mathrm{Y})$ is binary regular open. Then $\mathrm{b}-\mathrm{cl}(\mathrm{X}, \varnothing)=(\mathrm{X}, \mathrm{Y}) \subseteq(\mathrm{X}, \mathrm{Y})$. Therefore, $(\mathrm{X}, \varnothing)$ is generalized binary regular closed. But $(\mathrm{X}, \varnothing)$ is not generalized binary closed, since $(\mathrm{X}, \varnothing) \subseteq(\mathrm{X},\{\mathrm{a}, \mathrm{b}\})$ where $(\mathrm{X},\{\mathrm{a}, \mathrm{b}\})$ is binary open and $\mathrm{b}-\operatorname{cl}(\mathrm{X}, \varnothing)=(\mathrm{X}, \mathrm{Y}) \not \subset(\mathrm{X},\{\mathrm{a}, \mathrm{b}\})$.

Consider $(X,\{a\}) \in \wp(X) \times \wp(Y)$. Clearly, $(X,\{a\}) \subseteq(X, Y)$ where $(X, Y)$ is binary regular open. Then b-cl $(\mathrm{X},\{\mathrm{a}\})=(\mathrm{X}, \mathrm{Y}) \subseteq(\mathrm{X}, \mathrm{Y})$. Therefore, $(\mathrm{X},\{\mathrm{a}\})$ is generalized binary regular closed. But $(\mathrm{X},\{\mathrm{a}\})$ is not generalized binary closed, since $(X,\{a\}) \subseteq(X,\{a, b\})$ where $(X,\{a, b\})$ is binary open and b-cl $(X,\{a\})=$ $(\mathrm{X}, \mathrm{Y}) \not \subset(\mathrm{X},\{\mathrm{a}, \mathrm{b}\})$.

Proposition 3.7. If $A$ is regular open in $(X, \tau)$ and $B$ is regular open in $(Y, \sigma)$, then $(A, B)$ is binary regular open in $(\mathrm{X}, \mathrm{Y}, \tau \times \sigma)$.

Proof. By $[4], \tau \times \sigma$ is a binary topology from $X$ to $Y$.

The above Proposition is illustrated in the following.

\section{Illustration 3.8}

Consider $X=\{0,1\}$ and $Y=\{a, b, c\}$. Clearly $\tau=\{\varnothing,\{0\},\{1\}, X\}$ is a topology on $X$ and

$\sigma=\{\varnothing,\{a\},\{b\},\{a, b\}, Y\}$ is a topology on $Y$. The closed sets in $X$ are $\varnothing,\{0\},\{1\}, X$ and the closed sets in $\mathrm{Y}$ are $\varnothing,\{\mathrm{b} . \mathrm{c}\},\{\mathrm{a}, \mathrm{c}\},\{\mathrm{c}\}, \mathrm{Y}$. We see easily that $\{1\}$ is regular open in $\mathrm{X}$ and $\{\mathrm{a}\}$ is regular open in $\mathrm{Y}$. Now,$\tau \times \sigma=\{(\varnothing, \varnothing),(\varnothing,\{a\}),(\varnothing,\{b\}),(\varnothing,\{a, b\}),(\varnothing, Y),(\{0\}, \varnothing),(\{0\},\{a\})$, $(\{0\},\{b\}),(\{0\},\{a, b\}),(\{0\}, Y),(\{1\}, \varnothing),(\{1\},\{a\}),(\{1\},\{b\}),(\{1\},\{a, b\}),(\{1\}, Y),(X, \varnothing),(X,\{a\})$, $(X,\{b\}),(X,\{a, b\}),(X, Y)\}$.The binary closed sets are $(\varnothing, \varnothing),(X,\{b, c\}),(X,\{a, c\}),(X,\{c\}),(X, \varnothing)$, $(\{1\}, Y),(\{1\},\{b, c\}),(\{1\},\{a, c\}),(\{1\},\{c\}),(\{1\}, \varnothing),(\{0\}, Y),(\{0\},\{b, c\}),(\{0\},\{a, c\}),(\{0\},\{c\})$, $(\{0\}, \varnothing),(\varnothing, Y),(\varnothing,\{b, c\}),(\varnothing,\{a, c\}),(\varnothing,\{c\}),(\varnothing, \varnothing)\}$.

Now, b-int $(b-c l(\{1\},\{a\})=b-\operatorname{int}((\{1\},\{a, c\})=(\{1\},\{a\})$. Therefore, $(\{1\},\{a\}$,$) is binary regular open .$

If $(A, B)$ is generalized binary regular closed in a binary topological space $(X, Y, M)$, then A need not be generalized regular closed in $\left(\mathrm{X}, \mathrm{M}_{\mathrm{X}}\right)$ and $\mathrm{B}$ need not be generalized regular closed in $(\mathrm{Y}, \mathrm{M}$ y).This is shown in the following example.

Example 3. 9. Consider $X=\{0,1\}$ and $Y=\{a, b, c\}$.

Let $\mathrm{M}=\{(\varnothing, \varnothing),(\{0\},\{a\}),(\{1\},\{b\}),(X,\{a, b\}),(X, Y)\}$. Then $M$ is a binary topology from $X$ to $Y$. Clearly $M_{X}=\{\varnothing,\{0\},\{1\}, X\}$ is a topology on $X$ and $M_{Y}=\{\varnothing,\{a\},\{b\},\{a, b\}, Y\}$ is a topology on $Y$. The closed sets in $X$ are $\varnothing,\{0\},\{1\}, X$ and the closed sets in $Y$ are $\varnothing,\{b . c\},\{a, c\} \quad\{c\}, Y$. We can easily see that, $\varnothing,\{0\},\{1\}$ and $X$ are regular open in $X$ and $\varnothing,\{a\},\{b\}$ and $Y$ are regular open in $Y$.

Now, $(X,\{b\})$ is generalized binary regular closed. For, the binary regular open sets in $(X, Y, M)$ are $(\varnothing, \varnothing),(\{0\},\{a\}),(\{1\},\{b\}),(X, Y)$. Now, $(X,\{b\}) \subseteq(X, Y)$ where $(X, Y)$ is binary regular open. Then b-cl $(X,\{b\})=(X, Y) \subseteq(X, Y)$. Therefore, $(X,\{b\})$ is generalized binary regular closed. Also, $\{b\} \subseteq\{b\}$, where $\{b\}$ is regular open in $Y$. Therefore, $\operatorname{cl}\{b\}=\{b, c\} \not \subset\{b\}$.This shows that $\{b\}$ is not generalized regular closed in $\mathrm{Y}$ but $\mathrm{X}$ is generalized regular closed. 
Definition 3.10. Let ( $X, Y, M)$ be a binary topological space. Let $(A, B) \subseteq(X, Y)$. Then $(A, B)$ is called generalized binary regular open if $(\mathrm{X} \backslash \mathrm{A}, \mathrm{Y} \backslash \mathrm{B})$ is generalized binary regular closed.

Proposition 3.11. If $(A, B)$ is generalized binary open, then $(A, B)$ is generalized binary regular open.

Proof. Let $(A, B)$ be generalized binary open in a binary topological space ( $X, Y, M)$.

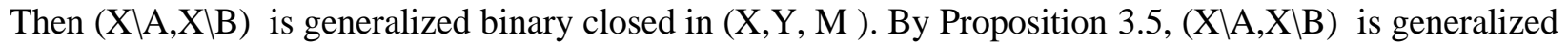
binary regular closed. Therefore, $(\mathrm{A}, \mathrm{B})$ is generalized binary regular open.

\section{Conclusion}

Regular open sets, regular closed sets, generalized regular closed sets and generalized regular open sets in topological spaces are extended to binary topological spaces. In this paper we introduced generalized binary regular closed sets and generalized binary regular open sets in binary topological spaces and their basic properties are studied.

\section{References}

[1] Engelking, Generel Topology, Polish Scientific Publishers, Warszawa (1977).

[2] W. Dunham, $\mathrm{T}_{1 / 2}$ - Spaces, Kyungpook Math J., 17(2)(1977), 161-169.

[3] W. Dunham, A new closure operator for non- $\mathrm{T}_{1}$ topologies, Kyungpook Math. J. 22(1)(1982), 55-60.

[4] S. Nithyanantha Jothi and P.Thangavelu, Topology between two sets, Journal of Mathematical Sciences \& Computer Applications, 1(3)(2011), 95-107.

[5] S. Nithyanantha Jothi and P.Thangavelu, On binary topological spaces, Pacific-Asian Journal of Mathematics, 5(2)(2011),133-138.

[6] S. Nithyanantha Jothi and P.Thangavelu, On binary continuity and binary separation axioms, Journal of Ultra Scientist Of Physical Sciences ,Vol.24(1)A,(2012),121-126.

[7] Norman Levine, Generalized closed sets in Topology, Rend. Cir. Mat. Palermo 2(1970), 89- 96

[8] S. Nithyanantha Jothi and P.Thangavelu, Generalized binary closed sets in binary topological spaces, Ultra Scientist Of Physical Sciences, Vol. 26(1)A, (2014),25-30.

[9] N. Palaniappan and K.Chandrasekhara Rao, Regular Generalized closed sets, Kyungpook Math. J.33(1993), 211-210. 